\title{
Podem os pós-auisos de esclarecimento eliminar a conformidade da memória?
}

\section{¿Pueden los post-auisos de clarificación eliminar la conformidad de la memoria? Can Enlightenment Post-Warnings Eliminate Memory Conformity?}

\author{
Delfina Fernandes \\ Pedro B. Albuquerque \\ Universidade do Minho \\ Karlos Luna \\ Universidad Nacional de Colombia
}

Doi: https://doi.org/10.12804/revistas.urosario.edu.co/apl/a.8375

\section{Resumo}

Após a discussão com outra testemunha sobre um acontecimento, as pessoas podem incorporar nas suas próprias memórias informações novas e erradas e, consequentemente incluí-las em relatos posteriores ao evento. Este fenómeno apelida-se de conformidade da memória. O presente estudo teve como objetivo perceber de que forma as testemunhas podem ser protegidas desta informação falsa utilizando pós-avisos de esclarecimento. Nesta investigação utilizou-se o procedimento MORI. Inicialmente, os participantes viram, em pares, um vídeo com duas versões que continham informação inconsistente. Seguidamente, discutiram detalhes do vídeo de forma a introduzir espontaneamente a informação falsa. Por fim, metade dos participantes receberam um pós-aviso de esclarecimento e, posteriormente, todos os participantes realizaram um teste de reconhecimento. Os resultados mostraram que a discussão entre testemunhas afetou a exatidão da memória, sendo menor para itens disputados durante a discussão do que para itens não disputados. Revelaram ainda que o pós-aviso de esclarecimento não eliminou a conformidade da memória. Assim, conclui-se que a informação enganosa introduzida pela discussão com outra testemunha tem uma influência tão forte na memória do evento que dificilmente é revertida. Desta forma, os relatos das testemunhas podem apresentar informações falsas, algo preocupante para o sistema legal.

Palavras-chave: conformidade da memória; esclarecimento; pós-aviso; procedimento MORI; testemunhas.

Delfina Fernandes ORCID ID: https://orcid.org/0000-0001-9670-2135

Pedro B. Albuquerque ORCID ID: https://orcid.org/0000-0002-5874-4497

Karlos Luna ORCID ID: https://orcid.org/0000-0001-8592-1172

Dirigir correspondência à Delfina Fernandes, Grupo de Investigação em Memória e Cognição Humana, Escola de Psicologia, Universidade do Minho, 4710-057, Gualtar, Portugal. Corréu eletrónico: delfin_fernandes@hotmail.com

Para citar este artigo: Fernandes, D., Albuquerque, P. B., \& Luna, K. (2020). Podem os pós-avisos de esclarecimento eliminar a conformidade da memória? Avances en Psicología Latinoamericana, 38(3), 1-15. https://doi.org/10.12804/revistas.urosario.edu.co/ap1/a.8375 


\section{Resumen}

Después de la discusión con otro testigo sobre un acontecimiento, las personas pueden incorporar en sus propias memorias informaciones nuevas y erradas $\mathrm{y}$, consecuentemente, incluirlas en relatos posteriores del evento. A este fenómeno se le llama conformidad de la memoria. El presente estudio tuvo como objetivo entender de qué forma los testigos pueden ser protegidos de esta información falsa utilizando post-avisos de clarificación. En esta investigación se utilizó el procedimiento MORI. Inicialmente, los participantes vieron, en parejas, un video con dos versiones que contenían información inconsistente. Luego, discutieron detalles del video con el objetivo de introducir de manera espontánea la información falsa. Al final, la mitad de los participantes recibieron un post-aviso de clarificación $\mathrm{y}$, a continuación, todos los participantes realizaron una prueba de reconocimiento. Los resultados mostraron que la discusión entre testigos afectó la exactitud de la memoria, siendo menor para ítems disputados durante la discusión que para ítems no disputados. Los resultados también revelaron que el post-aviso de clarificación no eliminó la conformidad de la memoria. Así, se concluye que la información engañosa introducida por la discusión con otro testigo tiene una influencia tan fuerte en la memoria del evento, que difícilmente es revertida. De esta forma, los relatos de los testigos pueden presentar informaciones falsas, algo preocupante para el sistema legal.

Palabras clave: conformidad de la memoria; clarificación; post-aviso; procedimiento MORI; testigos.

\section{fbstract}

After discussing with another witness an event, a person can incorporate new and false information in his/her own memories. That false information may appear in later accounts of the event, a phenomenon called memory conformity. The present study aimed to understand how witnesses can be protected from this false information using enlightenment post-warnings and the MORI technique. In pairs, each participant saw a different video that contained inconsistent information. Then, members of the pair discussed details of the video, and sometimes spontaneously introduced false information. Finally, half of the participants received an enlightenment post-warning, and then all participants completed a recognition test. The results showed that the discussion between witnesses impaired memory accuracy, showing the memory conformity effect. However, the enlightenment post-warnings did not reduce that effect. We conclude that the misleading information introduced by discussing with another witness has a strong influence on the memory of the event. In this way, the accounts of witnesses may contain false information difficult to get rid of, which is particularly worrying to the legal system.

Keywords: Enlightenment; memory conformity; MORI technique; post-warning; witnesses.

Após observar um crime, uma testemunha pode receber informação inconsistente com o que de facto presenciou através da polícia, jornais ou até de outras testemunhas. Esta informação pode comprometer a capacidade de reportar detalhes do acontecimento original, dando origem ao efeito da informação enganosa (Crozier \& Strange, 2019; Greene et al., 1982; Loftus et al., 1978; Oeberst \& Blank, 2012).

De facto, a transmissão de informação enganosa entre as testemunhas de um crime pode ser feita através da sua discussão sobre esse mesmo crime. Neste sentido, o que pode parecer tratar-se de uma "constatação" de ambas, pode ser o resultado da "contaminação" da memória de uma testemunha pelos comentários da outra (Gabbert et al., 2006). Neste caso, aquando da discussão com outra testemunha sobre o mesmo acontecimento, as pessoas podem incorporar informação nova e errada nas suas memórias e incluí-la em relatos posteriores ao acontecimento. Por exemplo, a cor do boné de um suspeito pode ser relatada por uma testemunha como vermelha, mas após a discussão com outra testemunha que acha que o boné é preto, a primeira testemunha pode assumir esta informação como fiável, criando uma memória falsa. Neste caso, a troca de informação enganosa entre testemunhas aquando da discussão dá origem ao fenómeno da 
conformidade da memória (French et al., 2011; Gabbert et al., 2003; Gabbert et al., 2006, 2007; Garry et al., 2008; Ito et al., 2019; Oeberst \& Seidemann, 2014; Paterson et al., 2011). Assim, a credibilização dos relatos testemunhados surgiu como uma grande preocupação do sistema legal e, por isso, a compreensão do fenômeno da conformidade da memória tem sido alvo de investigação.

Para estudar a conformidade da memória têm vindo a ser utilizadas várias metodologias. $\mathrm{Na}$ sua versão mais frequente, cada elemento de um par de participantes é levado a locais diferentes onde são apresentadas duas versões de um estímulo, por exemplo, imagens (Gabbert et al., 2006, 2007), vídeos (Paterson et al., 2011) ou áudios com a descrição de um incidente (Oeberst \& Seidemann, 2014). Posteriormente, os participantes são reunidos numa sala e levados a crer que ouviram ou viram a mesma informação, fazendo-os discutir o acontecimento. Existem também investigações sobre a conformidade social em que um comparsa é colocado junto dos participantes, gerindo a discussão e introduzindo a informação enganosa (Gabbert et al., 2004; Paterson \& Kemp, 2006). Por fim, existe ainda a técnica MORI ("Manipulation of Overlapping Rivalrous Images"; French et al., 2011; French et al., 2009; Garry et al., 2008; Ito et al., 2019) que, pela sua relevância para este trabalho, descrevemos em detalhe mais abaixo. Um resultado comum a estas metodologias para a investigação da conformidade da memória é o facto de os participantes reportarem menor exatidão da memória quando a informação enganosa é introduzida por outra testemunha durante a discussão (French et al., 2011; Gabbert et al., 2004; Gabbert et al., 2006; Garry et al., 2008; Ito et al., 2019; Oeberst \& Seidemann, 2014; Paterson \& Kemp, 2006; Paterson et al., 2011).

Relativamente à técnica MORI, esta envolve três etapas. Na primeira, pares de participantes veem lado-a-lado um vídeo, desconhecendo que este tem duas versões, ou seja, cada participante assiste um vídeo com detalhes diferentes do seu parceiro.
$\mathrm{O}$ aspeto crucial encontra-se no facto de haver dois projetores, um deles a transmitir ondas de luz num plano vertical e o outro num plano horizontal. Para isto, é colocado em frente à lente de um dos projetores um filtro polarizado no sentido vertical e na lente do outro projetor um filtro polarizado no sentido horizontal. Para que os participantes não percebam o objetivo da técnica, é-lhes dito que estariam a realizar uma experiência sobre acuidade visual e, para isso, teriam de colocar óculos polarizadores que, na realidade, bloqueavam uma das versões do vídeo projetado (a horizontal ou a vertical). Os dois vídeos apresentam detalhes diferentes (e.g., numa das versões o boné do indivíduo é preto e na outra versão é vermelho) designados por itens críticos. Na segunda etapa, são apresentadas questões referentes ao vídeo, uma de cada vez, com cinco alternativas de resposta (e.g., "O Eric experimentou um boné : Azul; Preto; Verde; Vermelho; Cinzento). Os participantes devem discutir as respostas às questões e dar uma resposta em conjunto. Na última etapa, os participantes realizam individualmente um teste de reconhecimento sobre o vídeo que visualizaram. Cada questão que contenha um item crítico apresenta duas alternativas de resposta que incluem os detalhes das duas versões do vídeo (e.g., "O Eric experimentou um boné : Vermelho; Preto).

A técnica MORI é a mais vantajosa em relação às outras metodologias para estudar a conformidade da memória, pois é a única em que é possível colocar duas testemunhas lado a lado que, aparentemente, assistem ao mesmo vídeo, no mesmo ecrã e ao mesmo tempo, mas na realidade, assistem a dois acontecimentos com detalhes diferentes sem que se apercebam disso. Tem também como vantagem o facto de serem as próprias testemunhas a apresentarem uma à outra a informação falsa, o que faz com que haja condições de investigação mais ecológicas do que se fosse o entrevistador ou um comparsa a gerarem a informação falsa (French et al., 2009). Tendo estas vantagens em conta, foi esta a técnica usada neste estudo. 
Estudos prévios mostraram que existem fatores que podem atenuar ou potenciar a conformidade da memória, por exemplo a (in)existência de disputa de opiniões durante a discussão (Gabbert et al., 2006; Garry et al., 2008) e a ordem de resposta à questão discutida (Gabbert et al., 2006, 2007; Garry et al., 2008). Um fator particularmente relevante, porque proporciona uma explicação para a conformidade da memória, são os julgamentos de credibilidade que atribuímos à nossa própria memória e à da outra testemunha. Os julgamentos de credibilidade podem ser absolutos, se avaliarmos a credibilidade da outra pessoa independentemente da nossa; ou relativos, se a compararmos com a nossa. French et al., (2011) mostraram que apenas os julgamentos relativos afetam a suscetibilidade à informação enganosa. Isto é, se o próprio sujeito se vê como mais credível, então será menos suscetível às sugestões enganosas de outra testemunha, ou pelo contrário, se vê o seu parceiro como mais credível, terá tendência a ser mais suscetível à informação enganosa (French et al., 2011; Gabbert et al., 2007; Goodwin et al., 2017; Horry et al., 2012; Skagerberg \& Wright, 2009).

Contudo, o desejável para o sistema legal não é atenuar a conformidade da memória, mas sim eliminá-la, evitando que ocorram falsas memórias nos testemunhos. Assim, a investigação tentou perceber quais são os facilitadores da resistência ao efeito da informação enganosa ou, uma vez instalada, que estratégias podem ser usadas para que o efeito seja eliminado. Uma destas estratégias é o uso de avisos que podem ser usados de duas formas, como pré-avisos e pós-avisos. Os pré-avisos funcionam como uma forma de alerta para possíveis informações enganosas e são apresentados antes das testemunhas poderem estar expostas a essa informação, por exemplo, alertar uma testemunha de que a descrição textual de um crime que irá ler foi escrita por um polícia inexperiente e por isso pode conter informação imprecisa. Literatura anterior mostrou que os avisos transmitidos antes da apresentação da informação falsa, apesar de não eliminarem, diminuíam de forma moderada o efeito de informação enganosa (Ecker et al., 2010; Greene et al., 1982), não havendo atualmente investigação sobre os pré-avisos no paradigma da conformidade da memória.

Alternativamente, existem os pós-avisos, que desencorajam as testemunhas a confiar na informação recebida após um acontecimento, sendo exibidos depois da informação enganosa ter sido processada (Blank \& Launay, 2014). Estes autores identificaram três dimensões não mutuamente exclusivas dos pós-avisos: especificidade, esclarecimento e descrédito social da fonte da informação. A especificidade refere-se a pós-avisos que localizam a informação enganosa no acontecimento (exemplo de um pós-aviso com especificidade alta: "no vídeo que viste, o Eric não tinha um boné preto"; e de um pós-aviso com especificidade baixa: "o teu parceiro pode ter mencionado detalhes que não apareceram no vídeo"). Quanto à segunda dimensão dos pós-avisos, o esclarecimento, o pós-aviso não só especifica a existência de informação enganosa, como também uma explicação para a sua presença (e.g., "Esta investigação é na realidade sobre psicologia da memória de testemunhos e a influência de informação enganosa depois de se presenciar um acontecimento e por isso pode ter recebido informação de duas fontes, o vídeo e o seu parceiro"). Por fim, no descrédito social da fonte da informação, o aviso é responsável por descredibilizar a competência de uma fonte por comparação com outra (e.g., "O teu parceiro era um comparsa da investigação e foi instruído a dar-te respostas com o objetivo de prejudicar o teu desempenho").

Alguns estudos sugerem que os pós-avisos reduzem o efeito da informação enganosa (Blank \& Launay, 2014). No entanto, Greene et al. (1982) não encontraram diminuição do efeito de informação enganosa quando o aviso foi inserido após a informação falsa ter sido processada (i.e., pós-aviso). A existência dos resultados contraditórios entre Greene et al. (1982) e Blank e Launay (2014) deve-se ao 
facto de os últimos autores terem concluído numa meta-análise sobre o efeito das três dimensões (especificidade, esclarecimento e descrédito social da fonte da informação) que a efetividade dos pós-avisos depende da dimensão manipulada. Especificamente, mostraram que os pós-avisos com a dimensão de esclarecimento eliminaram completamente o efeito de informação enganosa ao invés das outras dimensões que tinham menos influência na eliminação do efeito, por exemplo a especificidade baixa que foi utilizada por Greene et al. (1982). Estes resultados vieram corroborar os de Oeberst e Blank (2012) onde os autores utilizaram apenas pós-avisos com a dimensão de esclarecimento e mostraram que, depois da sua apresentação, o desempenho melhorou, isto é, as informações falsas foram menores, constatando que o esclarecimento é suficiente para eliminar o efeito de informação enganosa. Recentemente, Crozier e Strange (2019) também encontraram um efeito positivo dos pós-avisos na memória. Estes autores utilizaram correções, que são semelhantes a pós-avisos altamente específicos (e.g., "Eu vi o Eric num automóvel com o logótipo «AJ's». Ok, espere, eu vi o Eric num automóvel com o logótipo «RJ'S»»), e concluíram que os participantes que receberam estas correções mostraram uma diminuição efetiva do efeito de informação enganosa.

Quanto ao paradigma da conformidade da memória, a investigação com a utilização de pós-avisos é escassa. Paterson et al. (2011) apresentaram pós-avisos de baixa especificidade (e.g., "o teu parceiro pode ter visto uma versão do vídeo um pouco diferente da versão que tu viste") e concluíram que a conformidade da memória não era eliminada, uma vez que a informação enganosa partilhada entre testemunhas tem um impacto maior na memória. Contudo, esta investigação utilizou pós-avisos de baixa especificidade, que é sabido terem um efeito limitado, e não utilizou a metodologia mais ecológica e vantajosa, a técnica MORI. Desta forma, é necessária investigação sobre o efeito dos avisos na conformidade da memória no contexto que mais se aproxima de como esta ocorre na vida real e com a dimensão que apresenta mais vantagens.

Tal como referido anteriormente, a dimensão de esclarecimento tem sido apontada como a dimensão que possui mais vantagens. Isto é, a que melhor elimina o efeito de informação enganosa e a que cria uma melhor representação interna da tarefa durante o teste de memória. Em consequência, é a que mais motiva as testemunhas a recuperarem a informação original (Blank \& Launay, 2014; Oberst \& Blank, 2012). Os estudos também têm mostrado que é a dimensão que conduz a um processamento mais profundo das informações recebidas, fazendo com que as testemunhas percebam a (in)existência de discrepância entre o que está armazenado nas suas memórias e o que foi introduzido posteriormente ao evento original (Oberst \& Blank, 2012). Desta forma, os pós-avisos utilizados nesta investigação terão a dimensão de esclarecimento.

Esta investigação pretendeu preencher as lacunas supramencionadas e dessa forma englobou diversos objetivos. O primeiro referiu-se ao estudo da conformidade da memória em condições ecológicas recorrendo-se ao procedimento MORI. Neste procedimento a informação falsa é apresentada pelas próprias testemunhas, o que é uma vantagem comparativamente a outros procedimentos usados para estudar a produção de memórias falsas nos quais a informação falsa é apresentada pelo experimentador. $\mathrm{O}$ objetivo principal foi perceber de que forma as testemunhas podem ser protegidas desta informação falsa utilizando condições que se aproximam da realidade do contexto policial. Ou seja, através da apresentação de um aviso às testemunhas de que podem ter recebido informação inconsistente com a presenciada, depois desta informação ter sido processada (pós-aviso).

Tendo em conta os objetivos deste estudo, esperava-se que a exatidão da memória fosse menor quando a informação falsa fosse apresentada, independentemente de ter sido discutida, ou não, pelas testemunhas. No procedimento MORI os participantes têm a possibilidade de discutir entre si 
os itens onde a informação falsa foi apresentada. Nestes casos, às vezes uma testemunha diz algo que contradiz o que a outra testemunha viu (itens disputados). Assim, esperava-se que a exatidão da memória para os itens disputados também fosse prejudicada. Para além destas hipóteses, esperava-se que, com a adição de pós-avisos de esclarecimento, houvesse maior exatidão da memória do que se este não estivesse presente e, consequentemente, o efeito da conformidade da memória fosse eliminado.

O estudo da confiança das testemunhas no seu relato constituiu um objetivo secundário desta investigação, por um lado porque estudos prévios mostraram que a confiança expressada por uma testemunha no seu relato influencia a precisão e credibilidade atribuídas ao mesmo, por exemplo, por agentes policiais (Tetterton \& Warren, 2005), por outro porque a confiança faz parte dos processos cognitivos subjacentes ao relato de memórias (Weber \& Brewer, 2008). Adicionalmente, Horry et al (2014), investigaram a relação entre a confiança e a precisão num paradigma do efeito de informação enganosa, utilizando ainda um pós-aviso de especificidade baixa com todos os participantes. Uma vez que não houve um grupo em que não recebeu o pós-aviso, não é possível concluir o efeito deste na confiança. Contudo, estes autores mostraram que quando as informações não estão facilmente acessíveis na memória da testemunha, há uma relação fraca entre a precisão e a confiança das mesmas, sendo mais difícil para ela discriminar entre memórias reais e enganosas (Horry et al., 2014). Quanto ao paradigma da conformidade da memória, Goodwin et al. (2017) mostraram que a confiança que uma testemunha tem no seu relato espelha a confiança que o seu parceiro exibiu durante a discussão. Para além desta conclusão, foi observado que a confiança das testemunhas é menor para informações falsas fornecidas durante a discussão, do que para informações que confirmam o que estas assistiram (Goodwin et al., 2017). Atualmente não existe investigação sobre o efeito dos pós-avisos de esclarecimento na confiança das testemunhas e, por isso, não colocamos hipóteses sobre o seu efeito, ficando como um objetivo de tipo exploratório.

\section{Método}

\section{Participantes}

Participaram na experiência 80 estudantes, recrutados aos pares, o que perfaz um total de 40 pares. O tamanho da amostra foi calculado a partir do G*Power 3.1 (Faul et al., 2009). Ito et al. (2019) reportaram para uma amostra portuguesa um efeito da conformidade da memória muito forte, Hedges' $g=1,92$. A amostra necessária para detetar esse efeito com um poder estatístico de 0.80 e alfa $=0.05$ é de seis participantes. Para a interação hipotetizada entre a conformidade da memória e o pós-aviso baseamos o cálculo num efeito médio (Cohen's $f=0.25$ ), em que o resultado mostra ser necessária uma amostra de 34 participantes. Dos 80 participantes, 58 eram do sexo feminino e 22 do sexo masculino, com idades entre os 17 e os 33 anos $(M=19.3, D P=2.71)$. Metade dos participantes foram alocados à condição com pós-aviso de esclarecimento e a outra metade à condição sem o pós-aviso. Todos os estudantes realizaram a experiência voluntariamente sendo que alguns deles foram creditados pela sua participação.

\section{Planeamento}

Esta investigação recorreu a um plano experimental misto 2 (tipo de item: crítico, controlo) X 2 (pós-aviso: com pós-aviso, sem pós-aviso), com a primeira variável a ser manipulada intraparticipante e a segunda de forma interparticipante. A variável dependente deste estudo foi a exatidão da memória, operacionalizada através das respostas corretamente reconhecidas no teste de memória individual. Para além desta, existe uma segunda 
variável dependente: a confiança dos participantes nas suas respostas no teste individual de memória de reconhecimento.

Cada membro de um par de participantes foi alocado aleatoriamente a uma das duas versões do vídeo. Igualmente, metade dos pares foram alocados aleatoriamente a uma das duas versões da discussão. Para além disto, os pares de participantes foram ainda aleatorizados pela condição do pós-aviso (presença/ausência) e os itens críticos foram contrabalanceados, funcionando dessa forma tanto como informação falsa, como de controlo (dependendo da versão do vídeo).

\section{Materiais}

Nesta investigação foi utilizado o vídeo usado por Garry et al. (2008). O vídeo, com a duração de 6 minutos e 34 segundos, não tinha som e mostrava o eletricista "Eric" a trabalhar numa casa e a furtar alguns objetos da mesma. Este vídeo tinha duas versões que diferiam apenas em oito itens críticos. Por exemplo, numa versão do vídeo o boné de Eric era preto e na outra versão era vermelho.

A Figura 1 mostra o dispositivo da técnica MORI na qual esta experiência se baseou. Os vídeos foram transmitidos por dois projetores LED colocados um em cima do outro, fixados num suporte de metal, e que projetavam para um ecrã semitransparente $(45 \times 60 \mathrm{~cm})$, sendo que a imagem apenas era projetada em cerca de $30 \times 40 \mathrm{~cm}$ da área total do ecrã, localizado a aproximadamente $170 \mathrm{~cm}$ dos participantes. Os filtros polarizados foram colocados em frente a cada uma das lentes dos projetores, um no sentido vertical e o outro no sentido horizontal. Os óculos polarizadores que os participantes colocaram bloqueavam uma das projeções, ou a vertical ou a horizontal, acabando por verem apenas uma das versões do vídeo.

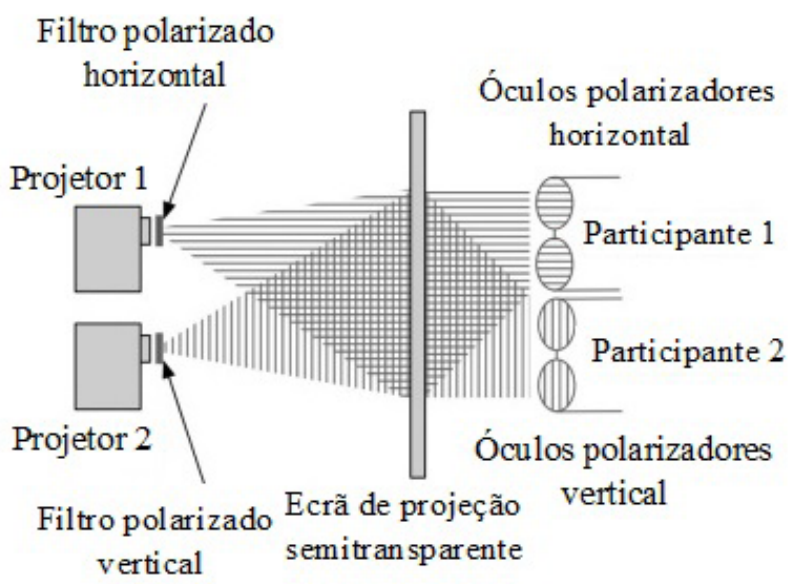

Figura 1. Disposição do equipamento para a técnica MORI

Fonte: adaptado de French et al. (2011).

\section{Procedimento}

O procedimento da investigação principal foi baseado no de Garry et al. (2008), tendo a duração de aproximadamente 45 minutos. Os participantes realizaram a experiência em pares. Inicialmente foi-lhes apresentado o consentimento informado e caso concordassem com todas as condições, dava-se início à experiência.

Primeiro, os participantes sentavam-se lado a lado, em frente a um ecrã para assistirem ao vídeo. Ao lado deles encontrava-se uma caixa que 
continha os óculos polarizadores. Essa caixa era de cartão e opaca para que os participantes não conseguissem ver o que a mesma continha. Nesse momento, foi-lhes explicado que para além de estarem a participar num estudo sobre memória e cognição humana, também estaríamos interessados em avaliar a sua acuidade visual para justificar a colocação dos óculos polarizadores. Após receberem esta informação os participantes começaram a primeira das três etapas com a visualização do vídeo do eletricista "Eric". Depois de assistirem o vídeo, os participantes retiravam os óculos polarizados e executavam uma tarefa de distração de sudoku durante 15 minutos.

Posteriormente deu-se início à segunda etapa do procedimento. Foram apresentadas no ecrã 12 questões, uma de cada vez, e foi pedido aos participantes que as discutissem e dessem uma resposta em conjunto. Os participantes tiveram um minuto para indicar a resposta e foram avisados quando faltassem 10 segundos para acabar o tempo. Cada questão tinha cinco alternativas de resposta, por exemplo "O Eric experimentou um boné Azul; Preto; Verde; Vermelho; Cinzento". Destas 12 questões, quatro referiam-se a itens críticos do vídeo e as restantes oito questões referiam-se a detalhes não críticos de forma a completar a tarefa, comuns nas duas versões. Nas alternativas de resposta a cada pergunta crítica estavam presentes as duas opções correspondentes a cada uma das versões dos vídeos. Se os participantes tivessem muita dificuldade em chegar a um acordo, eralhes permitido darem respostas diferentes. Esta opção não foi apresentada aos participantes logo de início, mas apenas no momento em que alguma pergunta gerasse dificuldade de acordo. No final desta segunda etapa os participantes trabalharam durante cinco minutos numa nova tarefa distrativa com vários problemas aritméticos.

Por fim, começou a terceira e última etapa em que os participantes realizaram individualmente um teste de reconhecimento. Metade dos pares de participantes receberam um pós-aviso escrito com a dimensão de esclarecimento, sendo que à restante metade dos pares não foi fornecido o pós-aviso. $\mathrm{O}$ pós-aviso de esclarecimento, baseado em Oeberst e Blank (2012), foi o seguinte:

\footnotetext{
Chegando a este ponto da experiência considero que devo dizer o objetivo principal do estudo e por isso deixar de o enganar. Esta investigação é na realidade sobre psicologia da memória de testemunhas e a influência de informação enganosa depois de se presenciar um acontecimento. Imagine que testemunhou um acidente de trânsito. Mais tarde pode discutir com outra testemunha o que assistiu ou até ver num jornal a notícia do acidente. Alguns detalhes do acidente podem ser contraditórios ao que realmente viu ou podem até estar em falta. Neste estudo simulamos uma situação semelhante. Você recebeu informação de duas fontes (vídeo e do seu colega) e a informação do colega pode ser correta ou incorreta. Seguidamente vai realizar um teste de memória sobre detalhes do vídeo que viu inicialmente. Nesses detalhes pode ter recebido apenas informação de uma das fontes ou pode ter recebido informação de duas fontes, que podem ser contraditórias ou consistentes entre si. Quando responder ao teste de memória tenha em conta apenas e exclusivamente a sua memória do vídeo! Depois ser-lhe-á pedido para indicar o quão confiante está da sua resposta.
}

Para os participantes que não receberam o pós-aviso a instrução foi a seguinte:

Agora vai responder a algumas perguntas sobre o vídeo que viu. Vamos testar a sua memória sobre o que você viu no vídeo. Cada questão tem duas partes: 1) na primeira parte, pergunta-se sobre um detalhe particular do vídeo; 2) na segunda parte, pergunta-se qual a sua confiança na sua própria resposta.

O teste de reconhecimento era constituído por 20 questões de escolha múltipla com duas alternativas, por exemplo, "O Eric experimentou um 
boné : Vermelho; Preto". Das 20 questões, oito avaliavam a memória para os quatro itens críticos e os quatro itens de controlo (que não foram discutidos). Nessas oito questões as alternativas eram constituídas pela informação das duas versões do vídeo, a que viu um dos participantes (resposta correta) e a que viu o parceiro (resposta incorreta). As 12 questões restantes eram referentes a detalhes do vídeo, comuns às duas versões, e serviam apenas para completar a tarefa. Após cada questão foi pedido aos participantes para avaliarem a confiança na sua resposta recorrendo a uma escala que variou entre 1 (nada confiante) e 5 (muito confiante).

Ametade dos pares que não recebeu o pós-aviso recebeu um debriefing pós-tarefa experimental, com a mesma informação do pós-aviso, em que lhe foi explicado o objetivo real da experiência. Como a informação era muito semelhante à do pós-aviso, o grupo com pós-aviso não recebeu o debriefing.

Os participantes foram ainda questionados se tinham alguma dúvida sobre a investigação e se em algum momento tinham percebido o objetivo da experiência. Todos os participantes ficaram surpreendidos com a explicação da metodologia e da existência de duas versões do vídeo. Finalmente, os participantes foram dispensados sendo-lhes agradecida a participação na investigação e pedido que não comentassem nenhum pormenor da experiência com os colegas, para que estes fossem ingénuos em relação aos objetivos e pormenores da experiência.

\section{Resultados}

Todas as análises estatísticas foram realizadas no software JASP (JASP Team, 2018). Antes de iniciar as análises correspondentes aos objetivos da investigação, começar-se-á por analisar as respostas às 12 questões do teste de memória de reconhecimento individual, referentes a detalhes não críticos do vídeo, funcionando como uma medida-base da memória. Para isto, realizou-se uma análise de variância (ANOVA) unifatorial com a manipulação dos pós-avisos (presença $v s$. ausência) como um fator interparticipante e a proporção média de respostas corretamente reconhecidas como medida. Não foram encontradas diferenças significativas na memória para estas 12 questões em função da presença $(M=0.85, D P=$ 0.10 , IC $95 \%[0.82,0.88])$ ou ausência $(M=0.85$, $D P=0.10$, IC $95 \%[0.81,0.88])$ do pós-aviso, $F$ $(1,78)=0.02, p=0.89, \eta_{p}^{2}<0.01$. Estes resultados mostram que, como era esperado, independentemente de os participantes serem avisados (ou não) da existência de informação inconsistente com o vídeo a que de facto assistiram, a sua memória foi semelhante nestes 12 itens em que não houve versões diferentes.

\section{Itens críticos vs. itens controlo}

Para analisar o efeito da exposição aos itens críticos e controlo foi realizada uma ANOVA mista 2 $\mathrm{x} 2$, com o tipo de item (crítico vs. controlo) como um fator intraparticipante, o pós-aviso (presença $v s$. ausência) como um fator interparticipante e a proporção de respostas corretamente reconhecidas no teste de memória individual como medida. Tal como se pode verificar pela Tabela 1 , os resultados evidenciaram efeitos principais do tipo de informação, $F(1,78)=14.79, p<0.001, \eta_{p}^{2}=0.16$, traduzido numa maior exatidão para os itens de controlo do que para os itens críticos (ou seja, com informação falsa). No entanto, a mesma análise revelou que não houve efeito do pós-aviso, $F(1$, $78)=0.25, p=0.62, \eta_{p}^{2}<0.01$, nem interação entre as duas variáveis, $F(1,78)=0.12, p=0.73$, $\eta_{p}^{2}<0.01$. 
Tabela 1

Média (desvio padrão) e [intervalo de confiança de 95\%] da proporção de respostas corretas para itens críticos e controlo dependendo do pós-aviso

\begin{tabular}{lccc}
\hline \multirow{2}{*}{ Condição } & \multicolumn{1}{c}{ Itens críticos } & Itens controlo & Total \\
\cline { 2 - 4 } & $M(D P)[\mathrm{IC}]$ & $M(D P)[\mathrm{IC}]$ & $M(D P)[\mathrm{IC}]$ \\
\hline Com pós-aviso & $0.59(0.27)[0.51,0.68]$ & $0.72(0.22)[0.65,0.79]$ & $0.66(0.18)[0.62,0.70]$ \\
\hline Sem pós-aviso & $0.60(0.24)[0.52,0.68]$ & $0.75(0.19)[0.69,0.81]$ & $0.68(0.15)[0.64,0.71]$ \\
\hline Total & $0.60(0.25)[0.54,0.65]$ & $0.73(0.20)[0.69,0.78]$ & \\
\hline
\end{tabular}

\section{Conformidade da memória e efeito do pós-aviso}

A investigação prévia identificou durante a etapa da discussão dois tipos de itens críticos diferentes: itens críticos disputados em que durante a discussão o participante foi exposto e aceitou a informação falsa apresentada pelo outro participante; e itens críticos não disputados em que não houve exposição à informação falsa ou esta não foi aceite (Garry et al., 2008; Ito et al., 2019). Foram classificados como itens disputados aqueles em que o participante foi exposto e aceitou a informação falsa durante a etapa da discussão, ou seja, respostas que contradiziam o que de facto tinha visto no vídeo. Por exemplo, quando um participante que viu o boné preto responde na discussão "vi um boné preto" e o segundo participante, que viu o boné vermelho, responde "também vi um boné preto", o item é classificado como disputado apenas para o segundo participante, pois foi quem recebeu a informação falsa. Por sua vez, se um participante que viu o boné preto responde "vi um boné preto", e o segundo participante que viu o boné vermelho responde "vi um boné vermelho", então o item é codificado como não disputado para os dois participantes, pois não houve transmissão de informação entre eles que possa ter criado uma falsa memória.

Relativamente à quantidade de itens disputados pelos participantes, realizou-se uma análise de variância (ANOVA) unifatorial com o pós-aviso (presença $v s$ ausência) como um fator interparticipante e a proporção de itens disputados por participante como medida. As análises mostraram que não houve diferenças significativas na média de itens disputados em função da presença $(M=1.43, D P=1.01$, IC $95 \%[1.10,1.75])$ ou ausência $(M=1.53, D P=0.96$, IC $95 \%[1.22,1.83])$ do pós-aviso, $F(1,78)=0.21, p=0.65 \eta_{p}^{2}<0.01$.

Assim, de forma a atender ao objetivo desta investigação relativo a se a discussão entre testemunhas afeta a exatidão da memória do acontecimento, foi realizada uma ANOVA mista 2 (tipo de item: disputado vs. não disputado) X 2 (pós-aviso: presença $v s$. ausência), com uma manipulação intraparticipante no primeiro fator e em que a unidade de medida foi a proporção de respostas corretamente reconhecidas no teste de memória individual. Tal como mostra a Tabela 2 , os resultados evidenciam um efeito principal do tipo de item, $F(1,63)=$ 257.41, $p<0.001, \eta_{p}^{2}=0.80$, traduzido numa maior exatidão para os itens não disputados do que para os itens disputados. No entanto, a mesma análise revelou que não houve efeito do pós-aviso, $F(1,63)$ $=0.46, p=0.50, \eta_{p}^{2}=0.01$, nem interação entre as duas variáveis, $F(1,63)=0.15, p=0.70, \eta_{p}{ }_{p}<0.01$.

Estas análises permitem também responder ao objetivo principal deste estudo, em que se pretendia investigar se a presença de um pós-aviso de esclarecimento seria preponderante para a eliminação da conformidade da memória. Tal como foi referido, os resultados mostram que não existem diferenças 
significativas na proporção de respostas corretamente reconhecidas entre os participantes que receberam o pós-aviso e os que não o receberam, mostrando que o pós-aviso de esclarecimento não conseguiu eliminar o fenómeno da conformidade da memória.

\section{Confiança}

Finalmente, tornou-se também relevante investigar a confiança das testemunhas nas respostas aos itens do teste de reconhecimento, ou seja, aos seus relatos posteriores ao evento, o que constituiu um objetivo secundário da investigação. Para isto, foi realizada uma ANOVA mista $2 \times 2$, com o tipo de item (disputados vs. não disputados) como um fator intraparticipante e o pós-aviso (presença $v s$. ausência) como um fator interparticipante. Tal como a Tabela 3 evidencia, os resultados mostraram um efeito principal do tipo de item, $F(1,62)$ $=9.03, p=0.004, \eta_{p}^{2}=0.13$, no sentido em que a confiança dos participantes foi maior para itens não disputados do que para itens disputados. Foi também possível observar um efeito principal do pós-aviso, $F(1,62)=4.24, p=0.04, \eta_{p}^{2}=0.06$, mostrando que quando os participantes recebiam o pós-aviso a confiança nas suas respostas diminuía, em comparação com os que não o receberam. No entanto, as análises revelaram não existir efeito de interação, $F(1,62)=0.10, p=0.76, \eta_{p}^{2}=0.01$.

\section{Discussão}

A presente investigação estudou a conformidade da memória em condições ecológicas com recurso do procedimento MORI, sendo a informação falsa apresentada pelas próprias testemunhas. O objetivo principal foi perceber de que forma as testemunhas podem ser protegidas desta informação falsa quando recebem pós-avisos de esclarecimento. Como objetivo secundário da investigação pretendeu estudar-se a confiança das testemunhas no seu relato.

Tabela 2

Média (desvio padrão) e [intervalo de confiança de 95\%] da proporção de respostas corretas para itens disputados e não disputados dependendo do pós-aviso

\begin{tabular}{lccc}
\hline \multirow{2}{*}{ Condição } & Itens disputados & Itens não disputados & Total \\
\cline { 2 - 4 } & $M(D P)[\mathrm{IC}]$ & $M(D P)[\mathrm{IC}]$ & $M(D P)[\mathrm{IC}]$ \\
\hline Com pós-aviso & $0.14(0.29)[0.03,0.25]$ & $0.85(0.23)[0.77,0.93]$ & $0.55(0.21)[0.50,0.60]$ \\
\hline Sem pós-aviso & $0.15(0.33)[0.04,0.27]$ & $0.90(0.20)[0.83,0.97]$ & $0.59(0.21)[0.54,0.63]$ \\
\hline Total & $0.15(0.30)[0.08,0.22]$ & $0.87(0.22)[0.82,0.92]$ & \\
\hline
\end{tabular}

Tabela 3

Média (desvio padrão) e [intervalo de confiança de 95\%] da confiança nas respostas dependendo do pós-aviso

\begin{tabular}{lccc}
\hline \multirow{2}{*}{ Condição } & \multicolumn{1}{c}{ Itens disputados } & Itens não disputados & Total \\
\cline { 2 - 4 } & $M(D P)[\mathrm{IC}]$ & $M(D P)[\mathrm{IC}]$ & $M(D P)[\mathrm{IC}]$ \\
\hline Com pós-aviso & $3.02(1.05)[2.63,3.40]$ & $3.66(0.95)[3.31,4.01]$ & $3.37(0.59)[3.24,3.50]$ \\
\hline Sem pós-aviso & $3.42(1.09)[3.03,3.81]$ & $3.94(0.98)[3.59,4.29]$ & $3.62(0.70)[3.47,3.78]$ \\
\hline Total & $3.22(1.08)[2.95,3.49]$ & $3.80(0.97)[3.56,4.04]$ & \\
\hline
\end{tabular}


Relativamente à exposição a informação falsa, esperava-se que nesta condição a exatidão das testemunhas fosse menor (Crozier \& Strange, 2019; Greene et al., 1982; Loftus et al., 1978; Oeberst \& Blank, 2012). Os resultados confirmaram esta hipótese pois a exatidão foi menor para os itens críticos que continham informação falsa do que para os itens controlo.

No procedimento MORI a informação falsa é apresentada na etapa em que ocorre a discussão. Durante esta etapa, às vezes uma testemunha diz algo que contradiz o que a outra testemunha viu, podendo qualquer uma das testemunhas experimentar a sensação de estar sujeita à informação falsa (i.e., itens disputados). Esperava-se que a exatidão da memória para os itens disputados fosse prejudicada. De forma a compreender o efeito da discussão na memória das testemunhas, as análises mostraram que os itens disputados apresentaram menor exatidão do que os itens não disputados, confirmando resultados prévios (French et al., 2011; Gabbert et al., 2006, 2007; Garry et al., 2008; Ito et al., 2019; Oeberst \& Seidemann, 2014; Paterson et al., 2011). Assim, é possível afirmar que a discussão com outra testemunha afeta a exatidão das suas memórias futuras sobre o crime que ambas assistiram.

Estas descobertas são bastante preocupantes para o sistema legal, uma vez que um depoimento de uma testemunha pode ser crucial para o desfecho de um processo ou investigação criminal. Agravando este facto, o estudo de estratégias que alertem as testemunhas de que podem ter recebido informação imprecisa através da discussão com outras testemunhas (pós-avisos) é muito escasso, o que justifica a relevância de investigar estas condições no paradigma da conformidade da memória. Este estudo permitiu preencher estas lacunas na investigação uma vez que estudou este fenómeno com a utilização dos pós-avisos. Além disso, a dimensão de esclarecimento tem sido apontada como a que melhor elimina o efeito de informação enganosa e a que cria uma melhor representação interna da tarefa. Em consequência, é a que mais motiva as testemunhas a recuperar a informação original (Blank \& Launay, 2014; Oberst \& Blank, 2012). Os estudos também têm mostrado que é a dimensão que conduz a um processamento mais profundo das informações recebidas, fazendo com que as testemunhas percebam a (in)existência de discrepância entre o que está armazenado na memória e o que foi introduzido posteriormente ao evento original (Oberst \& Blank, 2012). Assim, os pós-avisos utilizados neste estudo tiveram a dimensão de esclarecimento. Contudo, os resultados desta investigação mostraram que um pós-aviso com a dimensão de esclarecimento não foi suficiente para eliminar a conformidade da memória. Isto leva-nos a concluir que, mesmo que as testemunhas sejam avisadas de que podem ter sido expostas a informação inconsistente com a que presenciaram, os seus testemunhos podem continuar a relatar informações falsas.

Estes resultados vão ao encontro da ideia de que quando a informação enganosa é introduzida diretamente pela discussão com outras testemunhas, tem uma influência tão forte nas suas memórias que dificilmente é contornada, uma vez que aquela informação aparenta ser confiável e precisa (Gabbert et al., 2004; Paterson \& Kemp, 2006). Estes autores sugeriram que a discussão face a face entre duas pessoas contém informação adicional que pode influenciar as suas memórias. Essa informação encontra-se ao nível da comunicação não-verbal (e.g., contacto ocular, expressões faciais) e da formação de impressões (e.g., credibilidade da outra testemunha, confiança na mesma), justificando os resultados encontrados nesta investigação. Contudo, estas descobertas são também aplicáveis à informação que não contém detalhes falsos, ou seja, quando discutem informação consistente com o que de facto aconteceu. Nestes casos, a discussão com outra testemunha pode funcionar como reforço ou confirmação das suas memórias e o poder desta informação torna-se mais forte para relatos subsequentes. 
Nesta investigação foi também estudada a confiança das testemunhas nos seus relatos individuais. Os resultados mostraram que a confiança dos participantes foi maior para itens não disputados do que para itens disputados. Foi também observável que, em geral, a confiança dos participantes que receberam o pós-aviso era inferior à dos que não o receberam. Assim, conclui-se que, o pós-aviso diminuiu a confiança que as testemunhas tinham nos seus depoimentos. Tal como Tetterton e Warren (2005) investigaram, a confiança que uma testemunha tem sobre os seus relatos pode influenciar os procedimentos num processo legal, como por exemplo, a confiabilidade dos polícias nas suas declarações. Desta forma, o facto de neste estudo haver diferenças na confiança que as testemunhas tinham nos seus relatos, conduzem a uma redução da credibilidade dos mesmos.

Relativamente às limitações da investigação destaca-se o facto de o pós-aviso utilizado possuir a dimensão de esclarecimento. Apesar desta dimensão possuir diversas vantagens, pode não ser possível a sua aplicação direta num contexto policial. Contudo, em contexto real, as testemunhas podem ser alertadas de forma análoga ao esclarecimento utilizado. Isto é, podem ser avisadas de que podem ter recebido informação de diferentes fontes após o evento testemunhado (e.g., jornais, outras testemunhas) e alguma dessa informação pode ser inconsistente com as suas perceções e memórias do evento. No entanto, estes procedimentos necessitam de mais investigação.

Ainda sobre as limitações desta investigação, os resultados mostraram que o pós-aviso com a dimensão de esclarecimento não teve qualquer efeito na eliminação da conformidade da memória. Uma das explicações encontradas foi o facto de a discussão com outras testemunhas ter uma influência tão forte na memória que dificilmente é contornada pela apresentação de informação prévia que alerte para esse problema. Contudo, existe outra possibilidade: o facto de o pós-aviso baseado no estudo de informação enganosa de Oeberst e Blank (2012), ao ser traduzido para o paradigma da conformidade da memória, ter perdido a sua efetividade. Por outras palavras, o aviso poderá ter que ser diferente em estudos sobre o efeito da informação enganosa e sobre a conformidade da memória, podendo o aviso aplicado neste estudo não ter informação suficiente para o procedimento MORI. Investigação futura terá de estudar esta explicação alternativa e as possíveis limitações dos avisos com esclarecimento no paradigma da conformidade da memória.

Em estudos futuros, seria ainda importante analisar, juntamente com os pós-avisos, outras variáveis que interferem com o fenómeno da conformidade da memória, como a credibilidade atribuída às testemunhas e a ordem da discussão, ou seja, quem iniciou a disputa dos itens e quem se conformou. Assim, seria possível compreender se com estas variáveis, que podem atenuar ou potenciar a conformidade da memória, o pós-aviso apresenta maior impacto numa das condições.

Em suma, é visível que se uma testemunha se defronta com informação enganosa apresentada pela discussão com outra testemunha, é altamente provável que incorpore essa informação nas suas memórias sobre o evento. Quando isso acontece, mesmo que sejam utilizadas estratégias que a alertem para a inconsistência da informação, é difícil que a testemunha recupere posteriormente a sua memória original, mostrando que o efeito da conformidade da memória é persistente. Este facto tem implicações preocupantes em contexto forense, principalmente para testemunhas oculares que têm um papel preponderante para a resolução de um crime e onde muitas vezes a consistência entre elas é fundamental para um parecer conclusivo do processo. De forma a minimizar os possíveis danos para o sistema legal, deve-se atuar ao nível da prevenção, isto é, evitar o quanto antes o contacto entre testemunhas e antecipar o mais cedo possível, após o evento, a entrevista do interrogatório policial para que haja menos probabilidade das testemunhas discutirem pormenores do crime. 


\section{Referências}

Blank, H., \& Launay, C. (2014). How to protect eyewitness memory against the misinformation effect: A meta-analysis of post-warning studies. Journal of Applied Research in Memory and Cognition, 3, 77-88. https://doi.org/10.1016/j. jarmac.2014.03.005

Crozier, W., \& Strange, D. (2019). Correcting the misinformation effect. Applied Cognitive Psychology, 33, 585-595. https://doi.org/10.1002/acp.3499

Ecker, U. K. H., Lewandowsky, S., \& Tang, D. T. W. (2010). Explicit warnings reduce but not eliminate the continued influence of misinformation. Memory \& Cognition, 38, 1087-1100. https:// doi.org/10.3758/MC.38.8.1087

Faul, F., Erdfelder, E., Buchner, A., \& Lang, A. G. (2009). Statistical power analyses using $\mathrm{G}^{*}$ Power 3.1: Tests for correlation and regression analyses. Behavior Research Methods, 41, 1149-1160. https://doi.org/10.3758/ BRM.41.4.1149

French, L., Garry, M., \& Mori, K. (2011). Relative - not absolute - judgments of credibility affect susceptibility to misinformation conveyed during discussion. Acta Psychologica, 136, 119-128. https://doi.org/10.1016/j.actpsy.2010.10.009

French, L., Gerrie, M. P., Garry, M., \& Mori, K. (2009). Evidence for the efficacy of the MORI technique: Viewers do not notice or implicitly remember details from the alternate movie version. Behavior Research Methods, 41, 12241232. https://doi.org/10.3758/BRM.41.4.1224

Gabbert, F., Memon, A., \& Allan, K. (2003). Memory conformity: Can eyewitnesses influence each other's memories for an event? Applied Cognitive Psychology, 17, 533-543. https://doi. org/10.1002/acp.885

Gabbert, F., Memon, A., Allan, K., \& Wright, D. B. (2004). Say it to my face: Examining the effects of socially encountered misinformation. Legal and Criminological Psychology, 9, 215-227. https://doi.org/10.1348/1355325041719428
Gabbert, F., Memon, A., \& Wright, D. B. (2006). Memory conformity: Disentangling the steps towards influence during a discussion. Psychonomic Bulletin \& Review, 13, 480-485. https:// doi.org/10.3758/BF03193873

Gabbert, F., Memon, A., \& Wright, D. B. (2007). I saw it for longer than you: The relationship between perceived encoding duration and memory conformity. Acta Psychologica, 124, 319-331. https://doi.org/10.1016/j.actpsy.2006.03.009

Garry, M., French, L., Kinzett, T., \& Mori, K. (2008). Eyewitness memory following discussion: Using the MORI technique with a Western sample. Applied Cognitive Psychology, 22, 431-439. https://doi.org/10.1002/acp.1376

Goodwin, K. A., Hannah, P. J., Nicholl, M. C., \& Ferri, J. M. (2017). The confident co-witness: The effects of misinformation on memory after collaborative discussion. Applied Cognitive Psychology, 31, 225-235. https://doi.org/10.1002/ acp. 3320

Greene, E., Flynn, M. S., \& Loftus, E. F. (1982). Inducing resistance to misleading information. Journal of Verbal Learning and Verbal Behavior, 21, 207-219. https://doi.org/10.1016/ S0022-5371(82)90571-0

Horry, R., Palmer, M. A., Sexton, M. L., \& Brewer, N. (2012). Memory conformity for confidently recognized items: The power of social influence on memory reports. Journal of Experimental Social Psychology, 48, 783-786. https://doi. org/10.1016/j.jesp.2011.12.010

Horry, R., Colton, L. M., \& Williamson, P. (2014). Confidence-accuracy resolution in the misinformation paradigm is influenced by the availability of source cues. Acta Psychologica, 151, 164-173. https://doi.org/10.1016/j.actpsy.2014.06.006

Ito, H., Barzykowski, K., Grzesik, M., Gülgöz, S., Gürdere, C., Janssen, S., Khor, J., Rowthorn, H., Wade, K. A., Luna, K., Albuquerque, P. B., Kumar, D., Deep Singh, A., Weber Cecconello, W., Cadavid, S., Laird, N. C., Baldassari, M. J., 
Lindsay, D. S., \& Mori, K. (2019). Eyewitness memory following co-witness discussion: A replication of Garry, French, Kinzett, and Mori (2008) in ten countries. Journal of Applied Research in Memory and Cognition, 8, 68-77. https://doi.org/10.1016/j.jarmac.2018.09.004

JASP Team. (2018). JASP (Version 0.9) [Computer software]

Loftus, E. F., Miller, D. G., \& Burns, H. J. (1978). Semantic integration of verbal information into a visual memory. Journal of Experimental Psychology: Human Learning and Memory, 4, 19 31. https://doi.org/10.1037/0278-7393.4.1.19

Oeberst, A., \& Blank, H. (2012). Undoing suggestive influence on memory: The reversibility of the eyewitness misinformation effect. Cognition, 125, 141-159. https://doi.org/10.1016/j.cognition.2012.07.009

Oeberst, A., \& Seidemann, J. (2014). Will your words become mine? Underlying processes and co-witness intimacy in the memory conformity paradigm. Canadian Journal of Experimental Psychology, 68, 84-96. https://doi.org/10.1037/ cep0000014
Paterson, H., \& Kemp, R. (2006). Comparing methods of encountering post-event information: The power of co-witness suggestion. Applied Cognitive Psychology, 20, 1083-1099. https:// doi.org/10.1002/acp.1261

Paterson, H., Kemp, R., \& NG, J. R. (2011). Combating co-witness contamination: Attempting to decrease the negative effects of discussion on eyewitness memory. Applied Cognitive Psychology, 25, 43-52. https://doi.org/10.1002/acp.1640 Skagerberg, E. M., \& Wright, D. B. (2009). Susceptibility to post-identification feedback is affected by source credibility. Applied Cognitive Psychology, 23, 506-523. https://doi.org/10.1002/acp.1470

Tetterton, V. S., \& Warren, A. R. (2005). Using witness confidence can impair the ability to detect deception. Criminal Justice and Behavior, 32, 433-451. https://doi.org/10.1177/ 0093854805276406

Weber, N., \& Brewer, N. (2008). Eyewitness recall: Regulation of grain size and the role of confidence. Journal of Experimental Psychology: Applied, 14, 50-60. https://doi.org/10.1037/1076898X.14.1.50 